\title{
Effects of different protein sources on nutrient disappearance, rumen fermentation parameters and microbiota in dual-flow continuous culture system
}

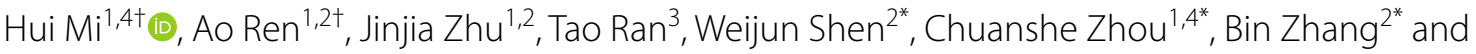 \\ Zhiliang $\operatorname{Tan}^{1,4}$
}

\begin{abstract}
Scarce high-quality protein feed resources has limited the development of animal husbandry. In this study, we used a dual-flow continuous culture system to evaluate effects of difference dietary protein sources including soybean meal (SBM), cottonseed meal (CSM), and rapeseed meal (RSM), on nutrient disappearance, rumen fermentation, and microbiota of XiongDong black goats. Dietary proteins of either CSM, RSM or SBM had no effect on nutrient disappearance $(P>0.05)$. CSM or RSM significantly reduced $(P<0.01)$ the $\mathrm{pH}$ and enhanced $(P<0.01)$ the ammonia nitrogen $\left(\mathrm{NH}_{3}-\mathrm{N}\right)$ concentration in fermentation liquid compared to SBM. The short-chain fatty acids (SCFAs) contents were greater $(P=0.05)$ and acetate was lower $(P<0.01)$ in SBM than those in RSM and CSM, whereas propionate was greater $(P<0.01)$ in RSM than that in SBM, consequently reducing the acetate to propionate ratio (A/P) in RSM. Bacteroidetes, Firmicutes, and Proteobacteria were detected as the dominant phyla, and the relative abundances of Spirochaetae $(P<0.01)$ and Chlorobi $(P<0.05)$ declined in the CSM and RSM groups as compared to those in the SBM group. At the genus level, Prevotella_ 1 was the dominant genus; as compared to SBM, its relative abundance was greater $(P<0.01)$ in CSM and RSM. The abundances of Prevotellaceae_Ga6A1 and Christensenellaceae_R7 were lower $(P<0.05)$ in CSM, whereas Eubacterium_oxidoreducens_group, and Treponema_2 were lower $(P<0.01)$ in both CSM and RSM, and other genera were not different $(P>0.10)$. Although the bacterial community changed with different dietary protein sources, the disappearances of nutrients were not affected, suggesting that CSM and RSM could be used by rumen bacteria, as in case with SBM, and are suitable protein sources for ruminant diets.
\end{abstract}

Keywords: Protein sources, Nutrient disappearance, Rumen fermentation parameters, Microbiota, Dual-flow continuous culture system

*Correspondence: shenweijun@hunau.edu.cn; zcs@isa.ac.cn; zhb8236@126.com

${ }^{\dagger} \mathrm{Hui} \mathrm{Mi}$ and Ao Ren made equal contribution to this study

${ }^{1}$ CAS Key Laboratory for Agro-Ecological Processes in Subtropical Region, National Engineering Laboratory for Pollution Control and Waste Utilization in Livestock and Poultry Production, Hunan Provincial Key Laboratory of Animal Nutritional Physiology and Metabolic Process, Institute of Subtropical Agriculture, Chinese Academy of Sciences, Changsha 410125, Hunan, People's Republic of China

${ }^{2}$ College of Animal Science and Technology, Hunan Agricultural University, Changsha 410128, Hunan, People's Republic of China Full list of author information is available at the end of the article

\section{Introduction}

Proteins derived from plants, animals, and non-protein nitrogen are commonly used as crude protein $(\mathrm{CP})$ sources in ruminant diets. Soybean meal (SBM) has been the main protein source because of its relatively high concentration of $\mathrm{CP}$ and rumen-undegraded protein (RUP) and its well-balanced amino acid (AA) composition (Cherif et al. 2018). However, with the high and variable prices in recent years (Romero-Huelva et al. 2017), demand for alternatives to SBM to reduce feeding costs 
and enhance farm profits has increased (Cherif et al. 2018). Several agricultural byproducts such as rapeseed meal (RSM) and cottonseed meal (CSM), which are costeffective and easily available, have recently been used as protein sources in ruminant diets.

Numerous researchers have investigated the influence of various protein sources on nutrient digestibility and rumen fermentation in ruminants (Cherif et al. 2018; Paula et al. 2020; Sanchez-Duarte et al. 2019). Proteins from various sources usually have different chemical characteristics, such as AA composition, contents of rumen degradable protein (RDP) and RUP, and the RDP/ RUP. Differences in the chemical characteristics of diets are the main factors that affect digestibility, rumen fermentation characteristics and microbial exploitability of protein from different sources (Huang et al. 2019; Klevenhusen et al. 2017). Rumen fermentation and the microbial profile could be appropriately modified when goats were fed diets from different dietary protein sources, this could be due to the differences in the structure and degradability of different protein sources (Wang et al. 2009). The degradability of $\mathrm{CP}$ in the rumen is considerably related to the ruminal ammonia nitrogen $\left(\mathrm{NH}_{3}-\mathrm{N}\right)$ concentration, and McCarthy et al. (1989) reported a greater $\mathrm{NH}_{3}-\mathrm{N}$ concentration in SBM than that in corn gluten meal due to the higher ruminal degradability of SBM. Similarly, Cherif et al. (2018) reported that cows fed ground or rolled faba bean had higher ruminal $\mathrm{NH}_{3}-\mathrm{N}$ concentration than those fed SBM, which was because of higher solubility and degradability of $\mathrm{CP}$ in ground or rolled faba bean. However, protein sources have negligible effect on the digestibility of other nutrients in the rumen. McCarthy et al. (1989) found that digestion of organic matter (OM), starch, acid detergent fiber (ADF), and neutral detergent fiber (NDF) was not affected by dietary CP in the rumen. SBM and RSM could be partially replaced with feed grade urea or slow-release urea, without affecting milk performance or diet digestibility (Sinclair et al. 2012).

Both RSM and CSM are characterized to have a higher RUP content than that in SBM (NRC 2001). They are alternative sources of protein that can be used to replace SBM in ruminant diets. However, whether SBM replaced with CSM or RSM affects the production performance of animals remains uncertain, both negative (Imaizumi et al. 2016) and positive (Rutkowska et al. 2015; Shingfield et al. 2016) effects on ruminal fermentation and production performance have been observed when RSM and CSM were used in ruminant diets. We hypothesised that different alternative effects resulting from dietary protein sources might be associated with the transformation of the rumen microbiota. Numerous studies have highlighted that the type of diet can alter rumen microbiota
(Cremonesi et al. 2018; Klevenhusen et al. 2017; Niu et al. 2017). Furthermore, studies have focused on the association between dietary protein and rumen microbiota. He et al. (2018) found the high CP diets were beneficial for the growth of Butyrivibrio fibrisolvens because of the greater level of ammonia in the rumen of Holstein bulls. Wang et al. (2019) suggested that gastrointestinal tract microbial communities influences the utilization efficiency of nitrogen in goats. Zhang et al. (2020b) reported that reducing dietary $\mathrm{CP}$ content by $3 \%$ diminished the relative richness of Bacteroidetes, which might be associated with the increasing efficiency of carbohydrate utilization in the rumen. Most previous studies have concentrated on how protein levels affect ruminal microbiota, and the influence of different plant protein sources on ruminal bacterial communities has relatively not been examined. Therefore, this study aimed to use a dual-flow continuous culture system to evaluate effects of different dietary protein sources including SBM, CSM or RSM on nutrient disappearance, rumen fermentation and microbiota.

\section{Materials and methods}

This study was approved by the Animal Care Committee of the Institute of Subtropical Agriculture, Chinese Academy of Sciences, and the College of Animal Science and Technology, Hunan Agricultural University, Changsha, China.

\section{Continuous culture system}

We used a dual-flow continuous culture fermentation system because continuous culture fermenters run continuously for longer periods than in the Daisy ${ }^{\mathrm{II}}$, batch culture and the Ankon Gas Production System, furthermore, the continuous culture can mimic in vivo ruminal conditions and allows for natural stratification of feed particles, anaerobiosis, controlled temperature, and salivary buffering, similar to what occurs in the rumen (Alende et al. 2018). A dual-flow continuous culture system (Adebayo Arowolo et al. 2021) was used in this study. This system contains six fermentation units, each unit consisting of a fermentation apparatus, outflow device, liquid supply component, data detection module and controlling computer. The fermenter, with a working volume of $1000 \pm 20 \mathrm{~mL}$, is the center of each fermentation unit, and various sensors are installed on the fermenters to monitor the pressure, $\mathrm{pH}$ value and temperature in real time. The overflow device is connected to the overflow pipe of the fermenter. A solid discharger is installed at the bottom of the fermenter, and the gas flow meter, and $\mathrm{CO}_{2}$ and $\mathrm{CH}_{4}$ detectors are installed on the exhaust path to measure the exhaust volume and the $\mathrm{CO}_{2}$ and 
$\mathrm{CH}_{4}$ concentration in the fermenters used in this study (Shen et al. 2012).

\section{Experimental design and treatments}

The experiment was a replicated $3 \times 3$ Latin square design that evolved a dual-flow continuous culture fermentation system with six fermenters. The experimental diets were formulated and prepared as a total mixed ration (TMR), containing a forage: concentrate ratio of 50:50 (Table 1). Three different protein sources were used with the same CP content (12.26\%): SBM, RSM, and CSM. This study contained three periods and each period lasted 8 days, which included 5 days for adaptation and 3 days for sampling.

Three Xiongdong black goats (with an average body weight of $25.0 \pm 2.5 \mathrm{~kg}$ ) with permanent ruminal fistulas were used as rumen fluid donors. The goats were offered a TMR $(500 \mathrm{~g} / \mathrm{kg}$ maize straw, $315 \mathrm{~g} / \mathrm{kg}$ corn, $160 \mathrm{~g} / \mathrm{kg}$ soybean meal, $2.4 \mathrm{~g} / \mathrm{kg}$ calcium carbonate, $6.8 \mathrm{~g} / \mathrm{kg}$ calcium phosphate, $6.0 \mathrm{~g} / \mathrm{kg}$ sodium chloride, and $10 \mathrm{~g} / \mathrm{kg}$

Table 1 Composition and nutrient levels of basal diets (DM basis)

\begin{tabular}{|c|c|c|c|}
\hline \multirow[t]{2}{*}{ Item } & \multicolumn{3}{|c|}{ Treatments } \\
\hline & SBM & RSM & CSM \\
\hline \multicolumn{4}{|c|}{ Feed ingredients, $\%$ of DM } \\
\hline Corn & 31.50 & 30.00 & 30.00 \\
\hline Soybean meal & 16.00 & / & / \\
\hline Rapeseed meal & / & 19.04 & / \\
\hline Cottonseed meal & / & / & 16.50 \\
\hline Maize straw & 50.00 & 50.0 & 50.00 \\
\hline $\mathrm{CaCO}_{3}$ & 0.24 & 0.00 & 0.00 \\
\hline $\mathrm{Ca}_{3}(\mathrm{PO} 4)_{2}$ & 0.68 & 0.79 & 1.17 \\
\hline $\mathrm{NaCl}$ & 0.60 & 0.60 & 0.60 \\
\hline Premix ${ }^{a}$ & 1.00 & 1.00 & 1.00 \\
\hline \multicolumn{4}{|c|}{ Chemical composition (\%) } \\
\hline ME (Mcal/kg) & 2.19 & 2.19 & 2.19 \\
\hline $\mathrm{CP}$ & 12.26 & 12.26 & 12.26 \\
\hline RUP & 7.10 & 7.96 & 7.52 \\
\hline $\mathrm{RDP}$ & 6.98 & 3.96 & 3.89 \\
\hline SC & 33.83 & 37.05 & 36.55 \\
\hline NDF & 36.24 & 37.11 & 38.09 \\
\hline ADF & 25.89 & 26.64 & 26.74 \\
\hline $\mathrm{Ca}$ & 0.51 & 0.50 & 0.49 \\
\hline P & 0.32 & 0.43 & 0.44 \\
\hline
\end{tabular}

ME: Metabolic energy; CP: Crude protein; RUP, Rumen undegradable protein; SC: Structural carbohydrates; NDF: Neutral detergent fiber; ADF: Acid detergent fiber; Ca: Calcium; P: Phosphorus; RDP: Rumen degradable protein; SBM: Soybean meal; RSM: Rapeseed meal; CSM: Cottonseed meal ${ }^{a}$ The premix provided (per $\mathrm{kg}$ of the diet): $\mathrm{MgSO}_{4} \cdot \mathrm{H}_{2} \mathrm{O} 119 \mathrm{mg}$, $\mathrm{FeSO}_{4} \cdot \mathrm{H}_{2} \mathrm{O} 1.53 \mathrm{mg}, \mathrm{CuSO}_{4} \cdot 5 \mathrm{H}_{2} \mathrm{O} 0.8 \mathrm{mg}, \mathrm{MnSO}_{4} \cdot \mathrm{H}_{2} \mathrm{O} 3 \mathrm{mg}, \mathrm{ZnSO}_{4} \cdot \mathrm{H}_{2} \mathrm{O} 5 \mathrm{mg}$, $\mathrm{Na}_{2} \mathrm{SeO}_{3} 10 \mathrm{mg}, \mathrm{Kl} 40 \mathrm{mg}, \mathrm{CoCl}_{2} \cdot 6 \mathrm{H}_{2} \mathrm{O} 30 \mathrm{mg}, \mathrm{VA} 95000 \mathrm{IU}, \mathrm{VD} 17500 \mathrm{IU}$ and VE $18000 \mathrm{IU}$ premix with vitamins and microelements) twice daily in equal amounts (300 g per meal) at 08:00 and 18:00 h. Donor animals had free access to water and were adapted to diets 14 days before rumen fluid donation. Rumen contents were collected via the rumen cannula before morning feeding, and immediately transported to the laboratory in an insulated bottle pre-warmed with warm water $\left(39.5 \pm 0.5{ }^{\circ} \mathrm{C}\right)$. Then the rumen contents were squeezed through four layers of cheesecloth and mixed well. The $\mathrm{pH}$ was recorded, and samples were kept in a water bath with continuous release of $\mathrm{CO}_{2}$ prior to introducing into fermentation vessels.

Before starting the formal experiment, the inner surfaces of the fermentation vessels, $\mathrm{pH}$ meter, thermometer and mixing propeller were disinfected with $75 \%$ ethanol and then assembled ensure a gastight condition. To initiate fermentation, $500 \mathrm{~mL}$ of artificial saliva (which contained: $9.8 \mathrm{~g} \mathrm{NaHCO}_{3}, 9.3 \mathrm{~g} \mathrm{Na}_{2} \mathrm{PO}_{4} \cdot 12 \mathrm{H}_{2} \mathrm{O}, 0.47 \mathrm{~g} \mathrm{NaCl}$, $0.57 \mathrm{~g} \mathrm{KCl}, 0.12 \mathrm{~g} \mathrm{Mg} \cdot 7 \mathrm{H}_{2} \mathrm{O}$ and $0.04 \mathrm{~g} \mathrm{CaCl}_{2}$ per litter) (McDougall 1949) and $500 \mathrm{~mL}$ rumen inoculum were added to each fermenter through the feeder nose, and $20 \mathrm{~g}$ of the corresponding experimental diet was fed to each fermenter at 08:00 $\mathrm{h}$ on the first day of each period. The whole feeding process was performed with continuous $\mathrm{N}_{2}$ bubbling into fermenters to exhaust air (Brandao et al. 2018). After inoculation to fermenters, artificial saliva (McDougall 1949) was infused to maintain a liquid dilution rate of $6 \% / \mathrm{h}$. The effluent flow out of the fermenters was $\sim 1440 \mathrm{~mL}$ per day. The temperature was kept constant at $39.5 \pm 0.5{ }^{\circ} \mathrm{C}$ using warm water, and the rotation speed of the mixing propeller was set at $25 \mathrm{rpm}$ to simulate rumen peristalsis. Thereafter, $40 \mathrm{~g}$ of the diets were fed in two equal meals $(2 \times 20 \mathrm{~g})$ at $08: 00 \mathrm{~h}$ and 20:00 $\mathrm{h}$ on each day of the experimental period (Zhang et al. 2020a).

\section{Sample collection procedures}

At $08: 00 \mathrm{~h}$ on days 6,7 and 8 , samples were collected from total effluent before feeding and all samples were composited for three days (Fowler et al. 2015) for shortchain fatty acid (SCFAs) and $\mathrm{NH}_{3}-\mathrm{N}$ analysis. Briefly, $1.5-\mathrm{mL}$ of effluent was acidified using $0.15 \mathrm{~mL} 25 \%$ $(\mathrm{w} / \mathrm{v})$ metaphosphoric acid for analysis of SCFAs, and $1.5 \mathrm{~mL}$ of effluent was acidified with $0.15 \mathrm{~mL} \mathrm{H}_{2} \mathrm{SO}_{4}$ (1\% vol/vol) for $\mathrm{NH}_{3}-\mathrm{N}$ analysis. All samples were stored at $-20{ }^{\circ} \mathrm{C}$. Another $1.5-\mathrm{mL}$ of effluent sample was collected from each fermenter on each sampling day and stored at $-80{ }^{\circ} \mathrm{C}$, samples of three days were composited for DNA extraction(Firkins et al. 2015).The remaining effluent was handled to collect residuals for determining the in vitro nutrient disappearance using the method described by $\mathrm{Li}$ et al.(2016). The $\mathrm{pH}$ values were recorded using a $\mathrm{pH}$ meter inside the fermenter 
at 08:00 $\mathrm{h}$ before feeding on each of the sampling days, and $5 \mathrm{~mL}$ of fermentation fluid was collected from each fermenter into a container that containing $10 \mathrm{~mL}$ of methyl green solution (containing $1 \mathrm{~mL}$ methanol, $0.08 \mathrm{~g} \mathrm{NaCl}$ and $0.006 \mathrm{~g}$ methyl green) for protozoa counting (Shen et al. 2012).

\section{Chemical analysis}

The total nitrogen (TN) content was analyzed according to the methods of AOAC (2002) and the CP content was calculated as $\mathrm{TN} \times 6.25$. NDF and ADF were determined as reported by Van Soest et al. (1991) and AOAC (2002), respectively. The dry matter (DM) contents of residual feed, DM disappearance (DMD), NDF disappearance (NDFD) and ADF disappearance (ADFD) were determined following the procedures described by Zhang et al. (2018). The SCFAs concentration was measured using gas chromatography according to the procedure described by Harvatine et al. (2002), and the $\mathrm{NH}_{3}-\mathrm{N}$ concentration was determined using phenol-hypochlorite reaction method of Weatherburn (1967). For protozoa population counting, $1 \mathrm{~mL}$ mixed liquor was transferred to SedgewickRafter counting plate (Arthur Thomas no. 9851-C20) to count the protozoa population using a microscope with $100 \times$ magnification, the counting chamber is consisted of 1000 grids, and the total number of protozoa in 25 randomly selected grids was recorded as $\mathrm{N}$ using a five-point sampling method. The population of protozoa in fermenters were calculated by the following equation:

$$
\text { Protozoa population }=\mathrm{N} \times(1000 / 25) \times 3
$$

\section{DNA extraction and sequencing}

Total genomic DNA was extracted using DNA Extraction Kit (Qiagen, Germany) following the manufacturer's instructions. The quality and quantity of DNA were verified using NanoDropND1000 (NanoDrop Technologies, Inc, Wilmington, DE, USA) and agarose gel. Extracted DNA was diluted to a concentration of $1 \mathrm{ng} / \mu \mathrm{L}$ and used as templates for PCR amplification of bacterial 16S rRNA genes. The V3-V4 variable regions of $16 \mathrm{~S}$ rRNA genes were amplified with universal primers 343F (5'-TACGGR AGGCAGCAG-3') and 798R (5'-AGGGTATCTAAT CCT-3'), with different barcodes for each sample. The amplicon was visualized using gel electrophoresis, purified with AM Pure XP beads (Agencourt), and quantified using the Qubitds DNA assay kit. Bar-coded amplicons were mixed at equal molar ratios and subjected to Illumina paired-end library preparation, cluster generation, and 300-bp paired-end sequencing on an Illumina MiSeq PE300 instrument.

\section{Bioinformatic analysis}

Paired-end reads were preprocessed using Trimmomatic software (Bolger et al. 2014) to detect and cut off ambiguous bases $(\mathrm{N})$, and low-quality sequences. After trimming, paired-end reads were assembled using FLASH software (Reyon et al. 2012). The assembly parameters were: $10 \mathrm{bp}$ of minimal overlapping, $200 \mathrm{bp}$ of maximum overlapping and $20 \%$ of maximum mismatch rate. Reads with chimera were detected and removed using the QIIME software (version 1.8.0) (Caporaso et al. 2010). Clean reads were subjected to primer sequence removal and clustered to generate operational taxonomic units (OTUs) using UPARSE with $97 \%$ similarity cutoff (Edgar 2013). The representative reads of each OTU were selected using the QIIME package. All representative reads were annotated against Silva database (version 123) using the RDP classifier (Wang et al. 2007). Taxonomic identification and comparisons were performed at phylum and genus levels. Alpha diversity values were obtained using various diversity indices as described by Jiao et al. (2015). Principal coordinate analysis (PCoA) of the microbial communities was performed using the weighted UniFrac distance.

\section{Statistical analysis}

A $3 \times 3$ Latin square design with repetition was used in this study. All data were analyzed using SAS 9.2 (SAS 2009). Data on nutrient disappearance, fermentation parameters, protozoa counts, alpha diversity indices, relative abundances of bacteria at the phylum and genus levels were checked for normality (Kolmogorov-Smirov test) and variance homogeneity (F-test) before further statistical analysis. For variables that did not met the assumptions required for ANOVA (alpha diversity indices, relative abundances of bacteria), non-parametric test models were applied (Kruskal-Wallis procedure of $\mathrm{SAS}$ ). For variables that meet the assumptions required for ANOVA, the MIXED procedure was used to analyze the $\mathrm{pH}$ and protozoa counts, the model included the fixed effect of treatments, period, fermenter, sampling time and the interaction between treatment and sampling time. Sampling time was considered as the repeated measure, and the fermenter and experimental period were random effects. The nutrient disappearance, SCFAs and $\mathrm{NH}_{3}-\mathrm{N}$ levels were analyzed using one-way ANOVA. Statistical significance was accepted at $P<0.05$ and $0.05 \leq P \leq 0.1$ was considered as a trend.

\section{Results}

\section{In vitro nutrient disappearance}

The in vitro nutrient disappearance is shown in Table 2. The DMD, ranging from $78.59 \%$ to $79.41 \%$, did not differ 
Table 2 Nutrients digestibility affected by different protein source of diets

\begin{tabular}{llllll}
\hline Item & \multicolumn{2}{l}{ Treatments } & & SEM & P-Value \\
\cline { 2 - 4 } & SBM & RSM & CSM & & \\
\hline DMD (\%) & 78.78 & 78.59 & 79.41 & 1.24 & 0.98 \\
CPD (\%) & 77.89 & 70.37 & 75.71 & 2.01 & 0.25 \\
NDFD (\%) & 63.52 & 63.03 & 61.98 & 2.40 & 0.98 \\
ADFD (\%) & 73.47 & 71.85 & 74.31 & 1.79 & 0.93 \\
\hline
\end{tabular}

DMD: Dry matter disappearance; CPD: Crude protein disappearance; NDFD: Neutral detergent fiber disappearance; ADFD: Acid detergent fiber disappearance; SBM: Soybean meal; RSM: Rapeseed meal; CSM: Cottonseed meal

Table 3 Rumen fermentation parameters affected by different protein source of diets

\begin{tabular}{|c|c|c|c|c|c|}
\hline \multirow[t]{2}{*}{ Item } & \multicolumn{3}{|c|}{ Treatments } & \multirow[t]{2}{*}{ SEM } & \multirow[t]{2}{*}{$P$-Value } \\
\hline & SBM & RSM & CSM & & \\
\hline $\mathrm{pH}$ & $6.84^{a}$ & $6.68^{b}$ & $6.62^{b}$ & 0.03 & $<0.01$ \\
\hline $\mathrm{NH}_{3}-\mathrm{N}(\mathrm{mg} / \mathrm{dL})$ & $3.10^{b}$ & $4.63^{\mathrm{a}}$ & $5.46^{\mathrm{a}}$ & 0.38 & $<0.01$ \\
\hline Protozoa, $\times 10^{3}$ cells $/ \mathrm{mL}$ & 19.04 & 15.19 & 14.01 & 0.98 & 0.09 \\
\hline Acetate (\%) & $68.14^{a}$ & $65.19^{b}$ & $68.06^{\mathrm{a}}$ & 0.80 & $<0.01$ \\
\hline Propionate (\%) & $15.85^{b}$ & $18.30^{\mathrm{a}}$ & $16.50^{b}$ & 0.62 & $<0.01$ \\
\hline Butyrate (\%) & $10.63^{b}$ & $13.04^{\mathrm{a}}$ & $11.71^{b}$ & 1.30 & $<0.01$ \\
\hline Valerate (\%) & 2.18 & 1.80 & 1.84 & 0.12 & 0.33 \\
\hline Branch-chained SCFAs & $2.38^{a}$ & $2.25^{\mathrm{a}}$ & $1.88^{b}$ & 0.06 & $<0.01$ \\
\hline Total SCFAs (mM) & $119.73^{\mathrm{a}}$ & $102.13^{b}$ & $108.61^{b}$ & 6.03 & 0.05 \\
\hline Acetate/Propionate & $4.34^{\mathrm{a}}$ & $3.58^{b}$ & $4.16^{\mathrm{a}}$ & 0.11 & $<0.01$ \\
\hline
\end{tabular}

SBM: Soybean meal; RSM: Rapeseed meal; CSM: Cottonseed meal

${ }^{a}, b$ Mean values within a row with unlike superscript letters were significantly different $(P<0.05)$

among treatments $(P>0.10)$; CPD was also not affected $(P>0.10)$ by treatments, but the CPD in the SBM group was $10.68 \%$ numerically higher than that in the CSM group. Both NDFD and ADFD were not affected with different dietary protein sources in terms of fiber content $(P>0.10)$.

\section{Fermentation parameters and protozoa counting}

As presented in Table 3, the SBM treatment had significantly higher $\mathrm{pH}$ value $(P<0.01)$ and total SCFAs contents $(P=0.05)$ but lower $(P<0.01) \mathrm{NH}_{3}-\mathrm{N}$ concentrations than those in RSM and CSM treatments, with no differences observed between RSM and CSM $(P>0.05)$. The RSM treatment had a lower molar proportion of acetate $(P<0.01)$ and acetate to propionate ratio $(\mathrm{A} / \mathrm{P})(P<0.01)$ and a greater proportion of propionate $(P<0.01)$ and butyrate $(P<0.01)$ than those obtained from SBM and CSM treatment. The content of branchchained SCFAs in the CSM group was lower $(P<0.01)$

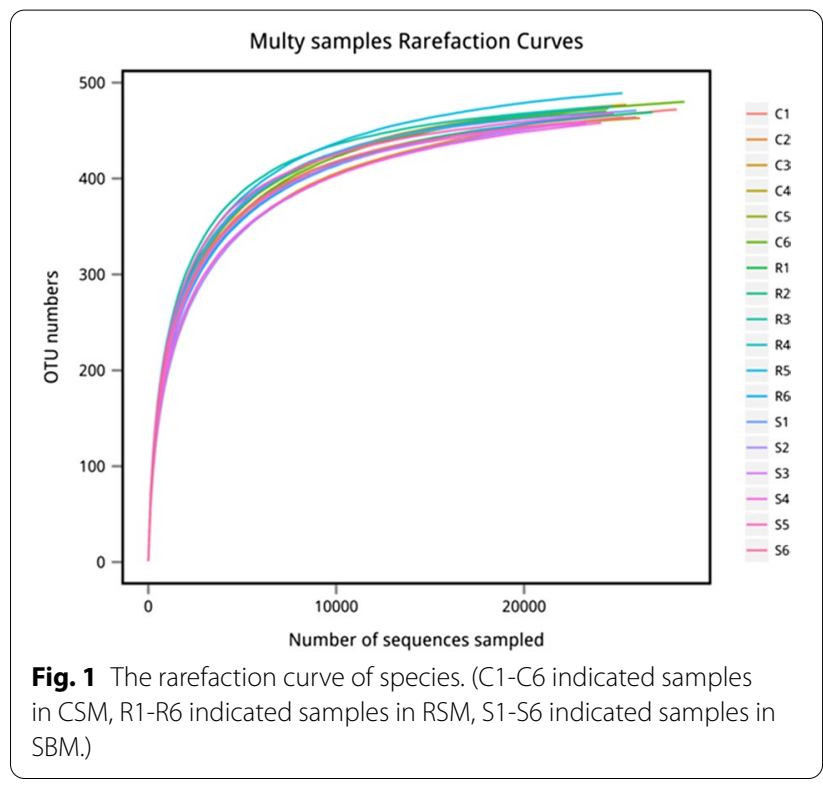

Table 4 Species richness, diversity and evenness indices of rumen bacteria affected by different protein source of diets

\begin{tabular}{lcccrl}
\hline & \multicolumn{2}{l}{ Treatments } & & \multirow{2}{*}{ SEM } & $P$-value \\
\cline { 2 - 4 } & \multicolumn{1}{c}{ SBM } & \multicolumn{1}{c}{ RSM } & \multicolumn{1}{c}{ CSM } & & \\
\hline OUTs number & $527.83^{\mathrm{b}}$ & $545.67^{\mathrm{a}}$ & $536.00^{\mathrm{ab}}$ & 2.94 & 0.03 \\
Chao & 566.53 & 587.82 & 572.80 & 5.91 & 0.07 \\
Shannon & 6.83 & 6.84 & 6.77 & 0.10 & 0.86 \\
Simpson & 0.98 & 0.97 & 0.97 & $<0.01$ & 0.75 \\
Coverage & 1.00 & 1.00 & 1.00 & $<0.01$ & 0.80 \\
ACE observed species & 523.67 & 539.00 & 528.67 & 4.57 & 0.08 \\
PD_whole_tree & 22.14 & 22.69 & 22.06 & 0.23 & 0.14 \\
\hline
\end{tabular}

SBM: Soybean meal; RSM: Rapeseed meal; CSM: Cottonseed meal

${ }^{\mathrm{ab}}$ Mean values within a row with unlike superscript letters were significantly different $(P<0.05)$

than that of SBM and RSM groups, whereas the valerate content did not differ among treatments $(P>0.10)$. The SBM treatment tended to have a greater $(P=0.09)$ protozoa enumeration than that from the RSM and CSM treatments (Table 3).

\section{Alpha and beta diversity}

The rarefaction curves (Fig. 1) indicated that all of our sampling efforts provided sufficient OTU coverage to accurately describe the bacterial composition of each group. The results of alpha diversity indices (Table 4) showed that the OTU number of RSM was significantly greater than that of $\operatorname{SBM}(P=0.03)$; chao and ACE indices tended to be greater $(0.05<P<0.10)$ in RSM. However, the Shannon, Simpson and coverage indices 
$(P>0.10)$ among three treatments were not significantly different. PCoA revealed that the samples of RSM and CSM treatment clustered and were separated from those of the SBM treatment, indicating that the bacterial diversity in the SBM group was different from that in RSM and CSM groups (Fig. 2).

\section{Bacterial taxonomy at the phylum and genus levels}

In all, 13 phyla were identified within the ruminal bacteria (Table 5), with the most dominant phyla being Bacteroidetes (59.37\%), Firmicutes (23.06\%), Spirochaetae (9.85\%), and Proteobacteria (5.71\%). The relative abundances of Spirochaetae $(P<0.01)$ and Chlorobi $(P=0.02)$ were lower in the RSM and CSM groups than in the SBM group. Meanwhile, the relative abundance of Actinobacteria tended to be greater $(P=0.06)$ in the RSM group than in the SBM group. The relative abundances of the other phyla did not differ among the three treatments $(P>0.10)$.

Among all the genera detected, only five genera significantly changed with different dietary protein sources (Table 6). Within the Bacteroidetes phylum, the relative abundances of Prevotella_1 in the CSM and RSM groups was increased by $42.23 \%$ and $32.89 \%$, respectively, compared with those in the SBM group $(P<0.01)$. The relative abundance of Prevotellaceae_Ga6A1_groupwas lower $(P=0.03)$ in the CSM group than in the SBM and CSM groups. The relative abundance of Prevotellaceae_UCG_003showed a significant difference $(P<0.01)$ among the three treatments, in the order of $\mathrm{CSM}>\mathrm{RSM}>\mathrm{SBM}$. Within the Firmicutes phylum, the

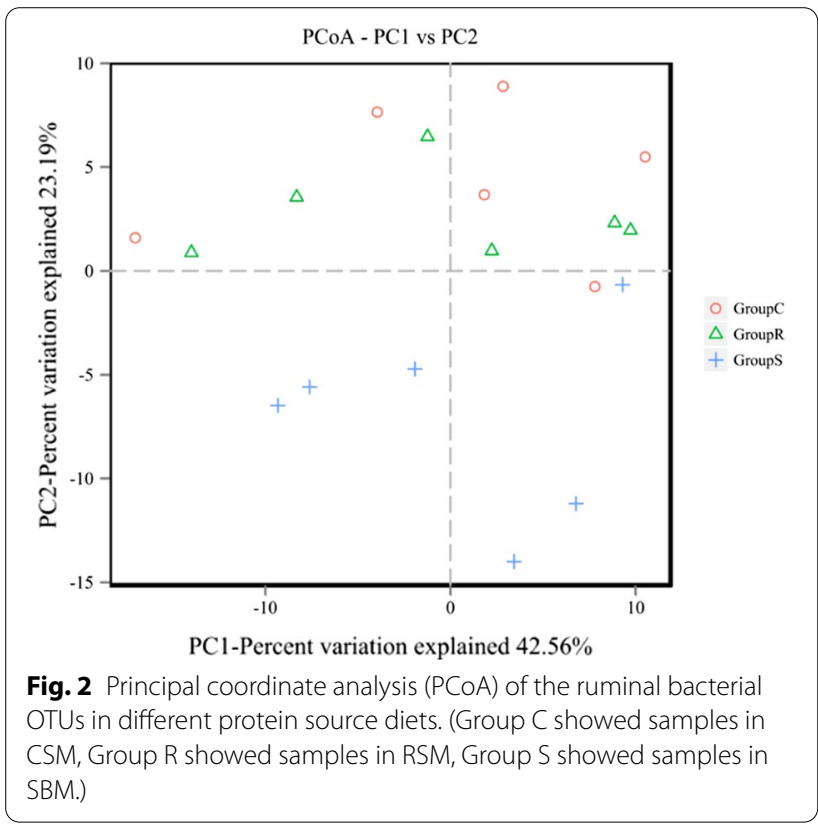

Table 5 Effects of different dietary protein source on the relative abundance (\%) of the ruminal bacterial at phylum level

\begin{tabular}{lccccc}
\hline Taxon & \multicolumn{2}{l}{ Treatments } & SEM & $P$-value \\
\cline { 2 - 4 } & SBM & RSM & CSM & & \\
\hline Bacteroidetes & 57.53 & 58.60 & 62.00 & 1.58 & 0.44 \\
Firmicutes & 24.48 & 23.04 & 21.67 & 0.88 & 0.46 \\
Spirochaetae & $8.71^{\mathrm{a}}$ & $4.14^{\mathrm{b}}$ & $4.27^{\mathrm{b}}$ & 0.64 & 0.01 \\
Proteobacteria & 7.39 & 11.84 & 10.31 & 1.49 & 0.46 \\
Fibrobacteres & 1.01 & 1.50 & 0.98 & 0.12 & 0.14 \\
Tenericutes & 0.52 & 0.48 & 0.39 & 0.04 & 0.28 \\
Lentisphaerae & 0.12 & 0.12 & 0.11 & 0.01 & 0.81 \\
Elusimicrobia & 0.12 & 0.14 & 0.19 & 0.03 & 0.91 \\
Chlorobi & $0.04^{\mathrm{a}}$ & $0.01^{\mathrm{b}}$ & $0.01^{\mathrm{b}}$ & 0.01 & 0.02 \\
Actinobacteria & 0.01 & 0.03 & 0.01 & 0.00 & 0.06 \\
Cyanobacteria & 0.00 & 0.01 & 0.02 & 0.00 & 0.55 \\
Saccharibacteria & 0.00 & 0.00 & 0.00 & 0.00 & 0.14 \\
Others & 0.06 & 0.09 & 0.05 & 0.01 & 0.22
\end{tabular}

SBM: Soybean meal; RSM: Rapeseed meal; CSM: Cottonseed meal

${ }^{\mathrm{ab}}$ Mean values within a row with unlike superscript letters were significantly different $(P<0.05)$

relative abundance of Eubacterium_oxidoreducens in the CSM and RSM groups was lower $(P<0.01)$ than that in the SBM group. Meanwhile, the relative abundance of Christensenellaceae_R_7 in the CSM group was lower $(P=0.03)$ than that in the SBM and RSM treatments. In the phylum Spirochaetae, Treponema_2 exhibited a relatively higher abundance in the SBM group than in the other two groups $(P<0.01)$.

\section{Discussion \\ Effects of dietary protein sources on in vitro nutrient disappearance}

In the current study, DMD, CPD, NDFD, and ADFD were not different among SBM, RSM and CSM treatments when an in vitro dual-flow continuous culture fermentation system was used. Our results agreed with those reported in the in vivo study by McCarthy (1989) that digestion of DM, ADF, and NDF in the rumen was not affected by dietary CP sources. RSM and CSM were reported to have lower RUP content than SBM (NRC 2001), Paula et al. (2017) found that SBM or canola meal with RUP ranging from 38 to $50 \%$ of CP did not affect nutrient digestion. When fed at the maintenance level, Zagorakis et al (2018) reported that sheep received diets used SBM, RSM and pea seeds as protein sources had similar digestibility of DM, CP, NDF, and ADF. In a more recent study, Tian et al. (2019) reported that the type of dietary protein source (SBM, CSM, or RSM) had no effect on the effective degradation rate of DM and $\mathrm{CP}$ in dairy cows. The main difference in dietary nutrient 
Table 6 Relative abundance (\%) of the most 30 abundant bacterial at genus level affected by different protein source of diets

\begin{tabular}{|c|c|c|c|c|c|c|}
\hline \multicolumn{2}{|l|}{ Taxon } & \multicolumn{3}{|c|}{ Treatments } & \multirow[t]{2}{*}{ SEM } & \multirow[t]{2}{*}{$P$-value } \\
\hline Phylum & Genus & SBM & RSM & CSM & & \\
\hline \multirow[t]{8}{*}{ Bacteroidetes } & Prevotellaceae_UCG_003 & $0.93^{c}$ & $1.39^{b}$ & $2.22^{\mathrm{a}}$ & 0.15 & $<0.01$ \\
\hline & Prevotella_1 & $18.72^{b}$ & $24.88^{\mathrm{a}}$ & $26.62^{\mathrm{a}}$ & 1.16 & 0.01 \\
\hline & Prevotellaceae_Ga6A1_group & $1.20^{\mathrm{a}}$ & $1.13^{\mathrm{a}}$ & $0.47^{\mathrm{b}}$ & 0.13 & 0.03 \\
\hline & Prevotellaceae_UCG_001 & 0.96 & 0.82 & 1.25 & 0.08 & 0.14 \\
\hline & U29_B03 & 0.25 & 0.47 & 0.27 & 0.05 & 0.17 \\
\hline & Haemonchus_placei & 0.82 & 0.97 & 1.19 & 0.14 & 0.50 \\
\hline & Rikenellaceae_RC9_gut_group & 7.40 & 7.61 & 7.93 & 0.50 & 0.83 \\
\hline & Bacteroides & 1.30 & 1.59 & 1.24 & 0.21 & 0.85 \\
\hline \multirow[t]{16}{*}{ Firmicutes } & [Eubacterium]_oxidoreducens_group & $0.85^{\mathrm{a}}$ & $0.18^{b}$ & $0.31^{b}$ & 0.10 & 0.01 \\
\hline & Christensenellaceae_R_7_group & $0.75^{\mathrm{a}}$ & $0.85^{\mathrm{a}}$ & $0.41^{\mathrm{b}}$ & 0.07 & 0.03 \\
\hline & Ruminococcaceae_UCG_010 & 0.37 & 0.58 & 0.46 & 0.04 & 0.09 \\
\hline & Ruminococcus_1 & 1.77 & 2.28 & 2.07 & 0.11 & 0.13 \\
\hline & Family_XIII_AD3011_group & 1.32 & 1.11 & 0.65 & 0.14 & 0.16 \\
\hline & Ruminiclostridium_5 & 0.89 & 0.66 & 0.69 & 0.05 & 0.19 \\
\hline & Butyrivibrio_2 & 0.43 & 0.39 & 0.35 & 0.02 & 0.24 \\
\hline & [Eubacterium]_coprostanoligenes_group & 0.82 & 0.65 & 0.67 & 0.05 & 0.31 \\
\hline & Lachnospiraceae_NK4A136_group & 0.88 & 0.94 & 0.92 & 0.06 & 0.33 \\
\hline & Papillibacter & 0.31 & 0.37 & 0.30 & 0.04 & 0.50 \\
\hline & Ruminococcaceae_UCG_014 & 3.24 & 3.64 & 3.98 & 0.26 & 0.53 \\
\hline & Anaerosporobacter & 0.54 & 0.54 & 0.83 & 0.20 & 0.63 \\
\hline & Ruminococcaceae_UCG_005 & 0.79 & 0.68 & 0.77 & 0.06 & 0.83 \\
\hline & Ruminococcaceae_UCG_002 & 0.78 & 0.68 & 0.77 & 0.11 & 0.75 \\
\hline & Saccharofermentans & 0.51 & 0.56 & 0.61 & 0.04 & 0.88 \\
\hline & Ruminococcaceae_NK4A214_group & 0.72 & 0.74 & 0.73 & 0.05 & 0.96 \\
\hline \multirow[t]{4}{*}{ Proteobacteria } & Thalassospira & 0.90 & 0.83 & 0.60 & 0.10 & 0.28 \\
\hline & Succinivibrionaceae_UCG_002 & 0.34 & 0.20 & 0.57 & 0.15 & 0.35 \\
\hline & Succinimonas & 4.98 & 8.61 & 7.73 & 1.42 & 0.57 \\
\hline & Ruminobacter & 0.27 & 0.57 & 0.22 & 0.12 & 0.70 \\
\hline Spirochaetae & Treponema_2 & $8.14^{\mathrm{a}}$ & $3.68^{b}$ & $3.83^{\mathrm{b}}$ & 0.62 & 0.01 \\
\hline Fibrobacteres & Fibrobacter & 0.99 & 1.48 & 0.95 & 0.12 & 0.14 \\
\hline
\end{tabular}

SBM: Soybean meal; RSM: Rapeseed meal; CSM: Cottonseed meal

${ }^{\mathrm{ab}}$ Mean values within a row with unlike superscript letters were significantly different $(P<0.05)$

composition in this study was the RDP content. Sun et al. (2019) reported that reducing the level of RDP in iso-nitrogenous diets had no effect on the apparent nutrient total-tract digestibility. All these studies suggested that RSM and CSM contained similar protein values and availability as SBM when included in ruminant diets. Moreover, this also suggested that the dual-flow continuous culture fermentation system is a feasible technology to mimic in vivo conditions.

\section{Effects of dietary protein sources on fermentation characteristics and protozoa population}

Rumen fermentation can be modified properly by different sources of dietary protein (Wang et al. 2009). Higher
RDP diets was expected to result in higher $\mathrm{NH}_{3}-\mathrm{N}$ concentrations (Agle et al. 2010); however, other studies have shown contrary results (Colmenero and Broderick 2006; Zhou et al. 2019), suggesting that RDP content was not always the main causes of $\mathrm{NH}_{3}-\mathrm{N}$ concentration, and that energy level and microbial protein synthesis efficiency also affect the $\mathrm{NH}_{3}-\mathrm{N}$ utilization (Russell et al. 1983). Besides, SBM treatment led to a greater total SCFAs concentration than CSM and RSM treatments, which were in accordance with $\mathrm{Xu}$ (2004). This is because RDP can either be used for microbial protein synthesis or be converted to SCFAs or $\mathrm{NH}_{3}-\mathrm{N}$, which was unpredictable in the rumen (Firkins et al. 2007). However, if less RDP is used for SCFAs production and microbial protein 
synthesis due to energy limitations, more RDP will be converted to $\mathrm{NH}_{3}-\mathrm{N}$, resulting in $\mathrm{NH}_{3}-\mathrm{N}$ accumulation (Russell et al. 1983). Taken together, we speculated that SBM was partially fermented to produce SCFAs instead of $\mathrm{NH}_{3}-\mathrm{N}$, thus leading to greater SCFAs production by SBM treatment than CSM or RSM treatments. The differences in acetate and propionate percentages and acetate/propionate indicated that SBM and CSM diets were beneficial for fatty acids synthesis and RSM diet was benefit for protein synthesis (Sutton and Morant 1989). Branched-chain SCFAs (isobutyrate and isovalerate) were reported to derived from dietary branchedchain amino acids (Hobson and Stewart 1997), which accounted for $17.08 \%, 16.11 \%$ and $13.22 \%$ of CP in soybean, rapeseed, and cottonseed, respectively (NRC 2001). Thus, in the current study, the lower molar proportion of branched-chain SCFAs in CSM treatment was likely due to the lower content of branched-chain amino acids in CSM, Which had the same tendancy as protozoa counts. Some protozoal species such as entodiniomorphid protozoa engulf starch and sequester it from bacteria preventing its rapid fermentation by lactic acid producing bacteria (Bonhomme 1990), this indicates that protozoa may be involed in $\mathrm{pH}$ regulation. In adult ruminants, ciliate protozoa account for the dominance of protozoa in the rumen (Fonty et al. 1988). Additionally, ciliates can phagocytose bacteria and fungi, which can use $\mathrm{NH}_{3}-\mathrm{N}$ to synthesize microbial proteins and promote their propagation (Chalupa 1976). This might be the reason why the number of protozoa in the SBM group tended to be higher than those in the RSM and CSM groups.

\section{Effects of dietary protein sources on rumen microbiota}

In all treatments, Firmicutes, Bacteroidetes and Proteobacteria were the dominant phyla, which was in accordance with the reports in dairy cows, goats, and beef cattle, regardless of the diet fed (Bickhart and Weimer 2018; Cremonesi et al. 2018; Zhou et al. 2019). This is because a core rumen microbial community is shared by ruminants, although the rumen microbial community composition varies with diet and host (Henderson et al. 2015). PCoA clustered the samples of different diet groups, suggesting that protein sources could affect the microbiota in the rumen. Notably, a greater relative abundance of Spirochaetae at the phylum level was observed in the SBM than in the RSM and CSM. Spirochetes plays an important role in degrading plant polymers materials such as xylan, pectin and arabinogalactan (Paster and CanaleParola 1982). Pectin contents was higher in SBM (1.6\%, $0.5 \%$ and $0.4 \%$ in SBM, RSM and CSM, respectively) (Zhu 2017). Thus, the difference of Spirochetes (Treponema_2 in particular) might associate with pectin content.
At the genus level, Prevotella_1 was the predominant genus, and its relative abundance was lower in SBM treatment when compared to RSM and CSM. The Prevotella genus has a wide metabolic niche due to genetic relatedness or high genetic variability that enables it to occupy different ecological niches within the rumen (Liu et al. 2019); thus; strains from the Prevotella genus are sensitive to dietary protein source. Another notable phenomenon lies in the fact that the Eubacterium_oxidoreducens_group, which belongs to Firmicutes phylum, was reduced in both the CSM and RSM groups.In the rumen, Eubacterium is associated with hemicellulolytic activity and usually produces organic acids (Taguchi et al. 2004). Because the NDF and ADF contents were similar in three diets, the surge in its abundance in the SBM diet might suggest that its potential role in protein degradation.

In conclusion, dietary protein sources could maintain stable ruminal fermentation, and the microbiota structure and relative abundance. Therefore, we believe that CSM and RSM are suitable protein sources in ruminant diets.

\section{Abbreviations \\ CP: Crude protein; SBM: Soybean meal; RUP: Rumen-undegraded protein; AA: Amino acid; RSM: Rapeseed meal; CSM: Cottonseed meal; RDP: Rumen degradable protein; $\mathrm{NH}_{3}-\mathrm{N}$ : Ammonia nitrogen; OM: Organic matter; ADF: Acid detergent fiber; NDF: Neutral detergent fiber; TMR: Total mixed ration; SCFAs: Short-chain fatty acid; DM: Dry matter; DMD: DM disappearance; TN: Total nitrogen; NDFD: NDF disappearance; ADFD: ADF disappearance; OTUs: Operational taxonomic units; PcoA: Principal coordinate analysis.}

\section{Acknowledgements}

Not applicable.

\section{Authors' contributions}

$\mathrm{CZ}, \mathrm{ZT}$ and BZ conceived and designed research. AR, JZ and HM conducted experiments. WS contributed new tools (dual-flow continuous culture system). AR and TR analyzed data. HM and AR wrote the manuscript. All authors read and approved the final manuscript.

\section{Funding}

The authors wish to acknowledge financial support received from the National Key point Research and Development Program of China (Nos. 2018YFD0501903, 2017YFD0500500), the National Natural Science Foundation of China (Nos. 31772632 31772633, 3177131525), the Youth Innovation Team Project of ISA, CAS (2017QNCXTD_ZCS), China Hunan Provincial Science \& Technology Department (2017JJ1028, 2017NK1020), the Major science and technology Project of Tibet Autonomous Region (No. XZ202101ZD003N), and the Science and Technology Project of Dazi city, Tibet Autonomous Region (No. XZDZKJ-2021-01)

\section{Data availability}

The rumen fluid $16 \mathrm{~S}$ rRNA-Seq data from this study have been submitted to the Sequence Read Archive (SRA) database (http://www.ncbi.nlm.nh. $\mathrm{gov} / \mathrm{sra}$ ) and the data are accessible through SRA Series accession number PRJNA758838 (http://www.ncbi.nlm.nih.gov/bioproject/758838).

\section{Code availability}

Not applicable. 


\section{Declarations}

Ethics approval and consent to participate

The experiment was approved by the Animal Care Committee, Institute of Subtropical Agriculture, Chinese Academy of Sciences, and College of Animal Science and Technology, Hunan Agricultural University, Changsha, China.

\section{Consent for publication}

Not applicable.

\section{Competing interests}

No potential conflict of interest was reported by the authors.

\section{Author details}

${ }^{1}$ CAS Key Laboratory for Agro-Ecological Processes in Subtropical Region, National Engineering Laboratory for Pollution Control and Waste Utilization in Livestock and Poultry Production, Hunan Provincial Key Laboratory of Animal Nutritional Physiology and Metabolic Process, Institute of Subtropical Agriculture, Chinese Academy of Sciences, Changsha 410125, Hunan, People's Republic of China. ${ }^{2}$ College of Animal Science and Technology, Hunan Agricultural University, Changsha 410128, Hunan, People's Republic of China. ${ }^{3}$ College of Pastoral Agriculture Science and Technology, Lanzhou University, Lanzhou 730000, Gansu, People's Republic of China. ${ }^{4}$ University of Chinese Academy of Sciences, Beijing 100049, People's Republic of China.

Received: 16 September 2021 Accepted: 29 January 2022

Published online: 10 February 2022

\section{References}

Adebayo Arowolo M, Zhang XM, Wang M, Wang R, Wen JN, Hao LZ, He JH, Shen WJ, Ma ZY, Tan ZL (2021) Proper motility enhances rumen fermentation and microbial protein synthesis with decreased saturation of dissolved gases in rumen simulation technique. J Dairy Sci 105(1):231-241. https://doi.org/10.3168/jds.2021-20165

Agle M, Hristov AN, Zaman S, Schneider C, Ndegwa P, Vaddella VK (2010) The effects of ruminally degraded protein on rumen fermentation and ammonia losses from manure in dairy cows. J Dairy Sci 93(4):1625-1637. https://doi.org/10.3168/jds.2009-2579

Alende M, Lascano GJ, Jenkins TC, Koch LE, Volpi-Lagreca G, Andrae JG (2018) Technical note: comparison of 4 methods for determining in vitro ruminal digestibility of annual ryegrass. Prof Anim Sci 34(3):306-309. https:// doi.org/10.15232/pas.2017-01688

AOAC (2002) Official methods of analysis, 16th edn. Association of Official Analytical Chemists, Washington

Bickhart DM, Weimer PJ (2018) Symposium review: host-rumen microbe interactions may be leveraged to improve the productivity of dairy cows. J Dairy Sci 101(8):7680-7689. https://doi.org/10.3168/jds.2017-13328

Bolger AM, Lohse M, Usadel B (2014) Trimmomatic: a flexible trimmer for Illumina sequence data. Bioinformatics 30(15):2114-2120. https://doi.org/ 10.1093/bioinformatics/btu170

Bonhomme A (1990) Rumen ciliates — their metabolism and relationships with bacteria and their hosts. Anim Feed Sci Tech 30(3-4):203-266. https://doi. org/10.1016/0377-8401(90)90016-2

Brandao VLN, Silva LG, Paula EM, Monteiro HF, Dai X, Lelis ALJ, Faccenda A, Poulson SR, Faciola AP (2018) Effects of replacing canola meal with solvent-extracted camelina meal on microbial fermentation in a dualflow continuous culture system. J Dairy Sci 101(10):9028-9040. https:// doi.org/10.3168/jds.2018-14826

Caporaso JG, Kuczynski J, Stombaugh J, Bittinger K, Bushman FD, Costello EK, Fierer N, Pena AG, Goodrich JK, Gordon Jl, Huttley GA, Kelley ST, Knights D, Koenig JE, Ley RE, Lozupone CA, McDonald D, Muegge BD, Pirrung M, Reeder J, Sevinsky JR, Turnbaugh PJ, Walters WA, Widmann J, Yatsunenko T, Zaneveld J, Knight R (2010) QIIME allows analysis of high-throughput community sequencing data. Nat Methods 7(5):335-336. https://doi.org/ 10.1038/nmeth.f.303

Chalupa W (1976) Degradation of amino acids by the mixed rumen microbial population. J Anim Sci 43(4):828-834. https://doi.org/10.2527/jas1976. $434828 x$
Cherif C, Hassanat F, Claveau S, Girard J, Gervais R, Benchaar C (2018) Faba bean (Vicia faba) inclusion in dairy cow diets: effect on nutrient digestion, rumen fermentation, nitrogen utilization, methane production, and milk performance. J Dairy Sci 101(10):8916-8928. https://doi.org/10.3168/jds. 2018-14890

Colmenero JJ, Broderick GA (2006) Effect of dietary crude protein concentration on milk production and nitrogen utilization in lactating dairy cows. J Dairy Sci 89(5):1704-1712. https://doi.org/10.3168/jds.S0022-0302(06) 72238-X

Cremonesi P, Conte G, Severgnini M, Turri F, Monni A, Capra E, Rapetti L, Colombini S, Chessa S, Battelli G, Alves SP, Mele M, Castiglioni B (2018) Evaluation of the effects of different diets on microbiome diversity and fatty acid composition of rumen liquor in dairy goat. Animal 12(9):18561866. https://doi.org/10.1017/\$1751731117003433

Edgar RC (2013) UPARSE: highly accurate OTU sequences from microbial amplicon reads. Nat Methods 10(10):996-998. https://doi.org/10.1038/ nmeth.2604

Firkins JL, Yu Z, Morrison M (2007) Ruminal nitrogen metabolism: perspectives for integration of microbiology and nutrition for dairy. J Dairy Sci 90(Suppl 1):E1-16. https://doi.org/10.3168/jds.2006-518

Firkins JL, Fowler CM, Devillard E, Bequette BJ (2015) Kinetics of microbial methionine metabolism in continuous cultures administered different methionine sources. J Dairy Sci 98(2):1178-1194. https://doi.org/10.3168/ jds.2014-8694

Fonty G, Senaud J, Jouany JP, Gouet P (1988) Establishment of ciliate protozoa in the rumen of conventional and conventionalized lambs: influence of diet and management conditions. Can J Microbiol 34(3):235-241. https:// doi.org/10.1139/m88-044

Fowler CM, Plank JE, Devillard E, Bequette BJ, Firkins JL (2015) Assessing the ruminal action of the isopropyl ester of 2-hydroxy-4-(methylthio) butanoic acid in continuous and batch cultures of mixed ruminal microbes. $J$ Dairy Sci 98(2):1167-1177. https://doi.org/10.3168/jds.2014-8692

Harvatine DI, Firkins JL, Eastridge ML (2002) Whole linted cottonseed as a forage substitute fed with ground or steam-flaked corn: digestibility and performance. J Dairy Sci 85(8):1976-1987. https://doi.org/10.3168/jds. S0022-0302(02)74274-4

He Y, Yu ZT, Qiu QH, Shao TQ, Niu WJ, Xia CQ, Wang HB, Su HW, Cao BH (2018) Effects of dietary protein levels and calcium salts of long-chain fatty acids on nitrogen mobilization, rumen microbiota and plasma fatty acid composition in Holstein bulls. Anim Feed Sci Tech 246:1-10. https://doi. org/10.1016/j.anifeedsci.2018.09.019

Henderson G, Cox F, Ganesh S, Jonker A, Young W, Global Rumen Census C, Janssen PH (2015) Rumen microbial community composition varies with diet and host, but a core microbiome is found across a wide geographical range. Sci Rep 5:14567. https://doi.org/10.1038/srep14567

Hobson PN, Stewart CS (1997) Microbe-microbe interactions, the Rumen microbial ecosystem. Springer, Dordrecht

Huang Y, Li R, Coulter JA, Zhang Z, Nan Z (2019) Comparative grain chemical composition, ruminal degradation in vivo, and intestinal digestibility in vitro of Vicia sativa L. varieties grown on the Tibetan Plateau. Animals. https://doi.org/10.3390/ani9050212

Imaizumi H, De Souza J, Batistel F, Santos FA (2016) Replacing soybean meal for cottonseed meal on performance of lactating dairy cows. Trop Anim Health Prod 48(1):139-144. https://doi.org/10.1007/s11250-015-0933-1

Jiao J, Huang J, Zhou C, Tan Z (2015) Taxonomic identification of ruminal epithelial bacterial diversity during rumen development in goats. Appl Environ Microbiol 81(10):3502-3509. https://doi.org/10.1128/AEM.00203-15

Klevenhusen F, Petri RM, Kleefisch MT, Khiaosa-Ard R, Metzler-Zebeli BU, Zebeli $Q$ (2017) Changes in fibre-adherent and fluid-associated microbial communities and fermentation profiles in the rumen of cattle fed diets differing in hay quality and concentrate amount. FEMS Microbiol Ecol. https:// doi.org/10.1093/femsec/fix100

Krumholz LR, Bryant MP (1986) Eubacterium-oxidoreducens Sp-Nov requiring $\mathrm{H}$-2 or formate to degrade gallate, pyrogallol, phloroglucinol and quercetin. Arch Microbiol 144(1):8-14. https://doi.org/10.1007/Bf00454948

Li D, Zhang Y, Cui Z, He L, Chen W, Meng Q, Ren L (2016) Effects of phytoecdysteroids (PEDS) extracted from Cyanotis arachnoidea on rumen fermentation, enzyme activity and microbial efficiency in a continuous-culture system. PLoS ONE 11(4):e0153584. https://doi.org/10.1371/journal.pone. 0153584 
Liu H, Xu T, Xu S, Ma L, Han X, Wang X, Zhang X, Hu L, Zhao N, Chen Y, Pi L, Zhao $X$ (2019) Effect of dietary concentrate to forage ratio on growth performance, rumen fermentation and bacterial diversity of Tibetan sheep under barn feeding on the Qinghai-Tibetan plateau. PeerJ 7:e7462. https://doi.org/10.7717/peerj.7462

McCarthy RD, Klusmeyer TH, Vicini JL, Clark JH, Nelson DR (1989) Effects of source of protein and carbohydrate on ruminal fermentation and passage of nutrients to the small intestine of lactating cows. J Dairy Sci 72(8):2002-2016. https://doi.org/10.3168/jds.S0022-0302(89)79324-3

McDougall El (1949) Studies on ruminant saliva. 1. The composition and output of sheeps saliva. Biochem J 43(1):99-109

Niu W, He Y, Xia C, Rahman MAU, Qiu Q, Shao T, Liang Y, Ji L, Wang H, Cao B (2017) Effects of replacing Leymus chinensis with whole-crop wheat hay on Holstein bull apparent digestibility, plasma parameters, rumen fermentation, and microbiota. Sci Rep 7(1):2114. https://doi.org/10.1038/ s41598-017-02258-2

NRC (2001) Nutrient requirements of dairy cattle, 7th edn. National Academies Press, Washington

Paster BJ, Canale-Parola E (1982) Physiological diversity of rumen spirochetes. Appl Environ Microbiol 43(3):686-693

Paula EM, Monteiro HF, Silva LG, Benedeti PDB, Daniel JLP, Shenkoru T, Broderick GA, Faciola AP (2017) Effects of replacing soybean meal with canola meal differing in rumen-undegradable protein content on ruminal fermentation and gas production kinetics using 2 in vitro systems. J Dairy Sci 100(7):5281-5292. https://doi.org/10.3168/jds.2016-12301

Paula EM, Broderick GA, Faciola AP (2020) Effects of replacing soybean meal with canola meal for lactating dairy cows fed 3 different ratios of alfalfa to corn silage. J Dairy Sci 103(2):1463-1471. https://doi.org/10.3168/jds. 2019-16947

Reyon D, Tsai SQ, Khayter C, Foden JA, Sander JD, Joung JK (2012) FLASH assembly of TALENs for high-throughput genome editing. Nat Biotechnol 30(5):460-465. https://doi.org/10.1038/nbt.2170

Romero-Huelva M, Ramirez-Fenosa MA, Planelles-Gonzalez R, Garcia-Casado P, Molina-Alcaide E (2017) Can by-products replace conventional ingredients in concentrate of dairy goat diet? J Dairy Sci 100(6):4500-4512. https://doi.org/10.3168/jds.2016-11766

Russell JB, Sniffen CJ, Van Soest PJ (1983) Effect of carbohydrate limitation on degradation and utilization of casein by mixed rumen bacteria. J Dairy Sci 66(4):763-775. https://doi.org/10.3168/jds.S0022-0302(83)81856-6

Rutkowska J, Bialek M, Bagnicka E, Jarczak J, Tambor K, Strzalkowska N, Jozwik A, Krzyzewski J, Adamska A, Rutkowska E (2015) Effects of replacing extracted soybean meal with rapeseed cake in corn grass silage-based diet for dairy cows. J Dairy Res 82(2):161-168. https://doi.org/10.1017/ S0022029915000060

Sanchez-Duarte Il, Kalscheur KF, Casper DP, Garcia AD (2019) Performance of dairy cows fed diets formulated at 2 starch concentrations with either canola meal or soybean meal as the protein supplement. J Dairy Sci 102(9):7970-7979. https://doi.org/10.3168/jds.2018-15760

SAS (2009) SAS/STAT 9.2 User's Guide: The MIXED Procedure. SAS Institute Inc, Cary

Shen W, Jiang Y, Wang J, Bu D, Shi H (2012) Design and testing of rumen simulation system with discharging solid chime, liquid, and gas respectively. $T$ Chinese Soc Agri Eng 28(3):20-26

Shingfield KJ, Vanhatalo A, Huhtanen P (2016) Comparison of heat-treated rapeseed expeller and solvent-extracted soya-bean meal as protein supplements for dairy cows given grass silage-based diets. Anim Sci 77(2):305-317. https://doi.org/10.1017/s135772980005904x

Sinclair LA, Blake CW, Griffin P, Jones GH (2012) The partial replacement of soyabean meal and rapeseed meal with feed grade urea or a slow-release urea and its effect on the performance, metabolism and digestibility in dairy cows. Animal 6(6):920-927. https://doi.org/10.1017/S175173111 1002485

Sun F, Aguerre MJ, Wattiaux MA (2019) Starch and dextrose at 2 levels of rumen-degradable protein in iso-nitrogenous diets: effects on lactation performance, ruminal measurements, methane emission, digestibility, and nitrogen balance of dairy cows. J Dairy Sci 102(2):1281-1293. https:// doi.org/10.3168/jds.2018-15041

Sutton JD, Morant SV (1989) A review of the potential of nutrition to modify milk fat and protein. Livest Prod Sci 23(3-4):219-237

Taguchi H, Koike S, Kobayashi Y, Cann IKO, Karita S (2004) Partial characterization of structure and function of a xylanase gene from the rumen hemicellulolytic bacterium Eubacterium ruminantium. Anim Sci J 75(4):325-332

Tian Y, Zhang X, Huang R, Yu P (2019) Protein molecular structure, degradation and availability of canola, rapeseed and soybean meals in dairy cattle diets. Asian-Australas J Anim Sci 32(9):1381-1388. https://doi.org/10. 5713/ajas.18.0829

Van Soest PJ, Robertson JB, Lewis BA (1991) Methods for dietary fiber, neutral detergent fiber, and nonstarch polysaccharides in relation to animal nutrition. J Dairy Sci 74(10):3583-3597. https://doi.org/10.3168/jds.S00220302(91)78551-2

Wang Q, Garrity GM, Tiedje JM, Cole JR (2007) Naive Bayesian classifier for rapid assignment of rRNA sequences into the new bacterial taxonomy. Appl Environ Microbiol 73(16):5261-5267. https://doi.org/10.1128/AEM. 00062-07

Wang RH, Wang MZ, Yu LH (2009) Effects of dietary protein sources on the rumen microorganisms and fermentation of goats. J Anim Vet Adv 8(7):1392-1401

Wang L, Liu K, Wang Z, Bai X, Peng Q, Jin L (2019) Bacterial community diversity associated with different utilization efficiencies of nitrogen in the gastrointestinal tract of goats. Front Microbiol 10:239. https://doi.org/10. 3389/fmicb.2019.00239

Weatherburn MW (1967) Phenol-hypochlorite reaction for determination of ammonia. Anal Chem 39(8):971-974. https://doi.org/10.1021/ac602 $52 \mathrm{a} 045$

Xu Z (2004) Rumen fermentation and microbial amino acid profile influenced by sources and levels of feed protein in vitro. master, Chinese Agriculture University

Zagorakis K, Liamadis D, Milis C, Dotas V, Dotas D (2018) Effects of replacing soybean meal with alternative sources of protein on nutrient digestibility and energy value of sheep diets. S Afr J Anim Sci 48(3):489-496. https:// doi.org/10.4314/sajas.v48i3.9

Zhang X, Wang M, Wang R, Ma Z, Long D, Mao H, Wen J, Bernard LA, Beauchemin KA, Tan Z (2018) Urea plus nitrate pretreatment of rice and wheat straws enhances degradation and reduces methane production in in vitro ruminal culture. J Sci Food Agric 98(14):5205-5211. https://doi. org/10.1002/jsfa.9056

Zhang J, Zheng N, Shen W, Zhao S, Wang J (2020a) Synchrony degree of dietary energy and nitrogen release influences microbial community, fermentation, and protein synthesis in a Rumen simulation system. Microorganisms 8(2):231. https://doi.org/10.3390/microorganisms8020231

Zhang XX, Li YX, Tang ZR, Sun WZ, Wu LT, An R, Chen HY, Wan K, Sun ZH (2020b) Reducing protein content in the diet of growing goats: implications for nitrogen balance, intestinal nutrient digestion and absorption, and rumen microbiota. Animal. https://doi.org/10.1017/S175173112 0000890

Zhou K, Bao Y, Zhao G (2019) Effects of dietary crude protein and tannic acid on rumen fermentation, rumen microbiota and nutrient digestion in beef cattle. Arch Anim Nutr 73(1):30-43. https://doi.org/10.1080/1745039X. 2018.1545502

Zhu JM (2017) Effects of NSPs in Rapeseed meal and Cottonseed Meal on Growth, Intestinal Morphology and Function of EniocheiY sinensis and explore of its mechanism. Su Zhou University

\section{Publisher's Note}

Springer Nature remains neutral with regard to jurisdictional claims in published maps and institutional affiliations. 